www.volsu.ru

DOI: https://doi.org/10.15688/jvolsu3.2018.3.10

UDC 338.124

LBC 65.7

\title{
STOCK BUBBLE LIFE-CYCLE AT EMERGING MARKETS AND STABILIZATION POLICY TUNING
}

\author{
Evgeniy B. Netunaev \\ Business Valuation Department, Baker Tilly Rus Consulting JSC; Lomonosov Moscow State University, \\ Moscow, Russian Federation
}

\begin{abstract}
Financial bubble on stock market (henceforward the stock market bubble) stays among the biggest challenges to economists. Its inflations and bursts damage financial system as well as the wider economy. This demands anti-bubble measures, whose efficiency however depends on their compliance with propagation mechanisms at different bubble life-cycle stages.

The paper suggests original model of stock market bubble life cycle that takes due account of developing markets. Stage separation is based on the ratio of rational (professional) investors to irrational (inexperienced) ones. We argue that there are irrational investors who inflate stock market bubbles with their over-optimistic expectations. Their congruent behavior incentivizes both themselves and their rational peers to adopt speculative strategies even though the bubble appears.

We develop the interaction algorithm for rational and irrational investors to identify five principle stages of stock market bubble life cycle. We prove that each stage provides for idiosyncratic stabilization measures. For example, the first stage, when not yet the bubble but its precondition matures, imposes indirect passive measures (e.g. stricter disclosure requirements for investment fund managers). The second and the third stages conversely involve direct active measures like verbal interventions and restrictions on trade operations for particular subgroups of investors. Monetary instruments may also come into play at the third stage, but in a supportive role.

Key words: financial bubble, stock market, emerging countries, stock bubble life-cycle, stock market stabilization policy.

Citation. Netunaev E.B. Stock Bubble Life-Cycle at Emerging Markets and Stabilization Policy Tuning. Vestnik Volgogradskogo gosudarstvennogo universiteta. Seriya 3, Ekonomika. Ekologiya [Science Journal of Volgograd State University. Global Economic System], 2018, vol. 20, no. 3, pp. 93-105. (in Russian). DOI: https://doi.org/10.15688/jvolsu3.2018.3.10
\end{abstract}

УДК 338.124

ББК 65.7

\section{ЖИЗНЕННЫЙ ЦИКЛ ФОНДОВОГО ПУЗЫРЯ В РАЗВИВАЮЩИХСЯ СТРАНАХ И «ТОНКАЯ НАСТРОЙКА» СТАБИЛИЗАЦИОННОЙ ПОЛИТИКИ}

\footnotetext{
Евгений Борисович Нетунаев

Департамент оценки бизнеса АО «Бейкер Тилли Рус Консалтинг»;

응 Московский государственный университет им. М. В. Ломоносова, г. Москва, Российская Федерация

บ

Аннотация. Финансовый пузырь на фондовом рынке (далее - фондовый пузырь) - один из сложнейших феноменов, изучаемых экономистами. Надувание и схлопывание фондового пузыря наносит ущерб как финансовому сектору, так и всей экономике. Этим обусловлена необходимость разработки мер противодействия пузырям, однако они могут оказаться недостаточно эффективными без понимания механизмов развития фондового пузыря на разных стадиях его жизненного цикла.
} 
В настоящей статье мы предлагаем оригинальную модель жизненного цикла фондового пузыря, учитывающую особенности фондовых рынков развивающихся стран. В основу выделения ключевых стадий цикла положено соотношение рациональных (квалифицированных) и иррациональных (неопытных) инвесторов на фондовом рынке. Мы доказываем, что формирование фондового пузыря происходит в результате избыточного оптимизма иррациональных инвесторов, который побуждает не только их самих, но и рациональных инвесторов следовать спекулятивным стратегиям даже в условиях надувания пузыря. Исходя из разработанной нами схемы взаимодействия рациональных и иррациональных инвесторов, мы идентифицировали 5 стадий развития фондового пузыря, для каждой из которых предложены наиболее эффективные стабилизационные меры. Так, на 1-й стадии, когда фондовый пузырь еще не образовался, но возникли предпосылки для его появления, финансовому регулятору целесообразно предпринимать косвенные сдерживающие меры (например, ужесточение требований к раскрытию информации управляющими фондами). На 2-й и 3-й стадиях необходимо использовать активные прямые меры: вербальные интервенции и ограничения торговых операций для разных групп инвесторов. При этом на 3-й стадии (когда фондовый пузырь достигает максимальных размеров) возможно применение ограничительной монетарной политики, но лишь в качестве вспомогательного инструмента.

Ключевые слова: финансовый пузырь, фондовый рынок, развивающиеся страны, жизненный цикл фондовых пузырей, стабилизационная политика на фондовом рынке.

Цитирование. Нетунаев Е. Б. Жизненный цикл фондового пузыря в развивающихся странах и «тонкая настройка» стабилизационной политики // Вестник Волгоградского государственного университета. Серия 3 , Экономика. Экология. -2018. - Т. 20, № 3. - C. 93-105. - DOI: https://doi.org/10.15688/jvolsu3.2018.3.10

\section{Введение}

Финансовый пузырь на фондовом рынке (далее по тексту - фондовый пузырь) является одним из сложнейших феноменов, изучаемых экономистами. Значительный ущерб, который способны нанести фондовые пузыри экономике, делает их актуальным объектом как теоретических, так и практических исследований в финансовых науках: существует большое количество работ, посвященных изучению различных аспектов природы фондового пузыря.

Однако нельзя утверждать, что активное изучение фондовых пузырей обусловлено чисто академическим интересом. Тот ущерб, который наносит фондовый пузырь финансовому и реальному секторам экономики, делает противодействие фондовым пузырям одной из важнейших задач борьбы за финансовую стабильность. Поэтому во многих исследованиях в качестве ключевого выступает вопрос: как можно предотвратить возникновение фондовых пузырей или уменьшить ущерб от их возникновения?

На этот вопрос трудно ответить без понимания механизмов развития жизненного цикла фондового пузыря. Только зная, что именно определяет динамику цен акций в долгосрочном периоде, можно выявить наиболее эффективные меры по профилактике фондового пузыря и/или элиминированию последствий его возникновения.

Цель настоящей статьи - предложить меры по минимизации ущерба от фондового пузыря, которые следует использовать финансовому регулятору в зависимости от стадии развития, на которой был идентифицирован пузырь. Для достижения данной цели мы провели анализ основных стадий жизненного цикла фондового пузыря. Это позволило уточнить перечень мер, которые целесообразно предпринимать финансовому регулятору на каждой стадии.

Статья построена следующим образом: в первой части мы описываем классическую модель жизненного цикла фондового пузыря, предложенную Кинлебергером, и выделяем недостатки, ограничивающие ее применение для анализа пузырей на фондовых рынках развивающихся стран. В следующем подразделе мы выделяем основные черты взаимодействия рациональных и иррациональных инвесторов, которое ведет к образованию фондовых пузырей. На основе модели взаимодействия рациональных и иррациональных инвесторов мы выделяем 5 стадий жизненного цикла фондового пузыря, для каждой из которых в заключительном подразделе предлагаем меры по предотвращению или уничтожению фондового пузыря. 


\section{Классическая модель} жизненного цикла фондового пузыря

Классическая модель, описывающая стадии, через которые проходит фондовый пузырь, представлена в работе Киндлебергера. Согласно его мнению, возникновение финансового пузыря происходит при сочетании кредитной экспансии и высоких темпов роста экономики. Высокие темпы роста экономики способствуют увеличению спроса на акции, что выражается в положительной динамике котировок. Кредитная экспансия способствует покупке акций с привлечением долговых средств, что положительно влияет на спрос на акции, что, по мнению Киндлебергера, провоцирует возникновение фондового пузыря. Киндлебергер выделил несколько стадий развития фондового пузыря:

1. Мания. На этой стадии начинается рост котировок акций и возникновение фондового пузыря. Положительная динамика котировок акций привлекает спекулянтов, которые не анализируют фундаментальную стоимость акций. Спекулянты стремятся как можно быстрее приобрести акции, чтобы не упустить спекулятивный доход, для чего активно привлекают заемные средства. Положительная динамика котировок акций (и следовательно, удачный опыт спекулятивных операций) стимулирует совершать новые спекулятивные сделки и покупать новые акции.

2. Дистресс. Инвесторы, успевшие приобрести акции на первой стадии (в своей работе Киндлебергер называет их инсайдерами) начинают фиксировать прибыль, продавая свои акции новым инвесторам (аутсайдерам, по терминологии Киндлебергера). Высокая доходность спекулятивных сделок, наблюдаемая на стадии «мания», привлекает аутсайдеров, что позволяет поддерживать положительную динамику котировок акций. Но часть аутсайдеров приходит к выводу, что цены достигли завышенного уровня и, опасаясь падения котировок, стараются продать имеющиеся акции, зафиксировав свою прибыль (то есть становятся инсайдерами). Чем больше появляется инсайдеров, тем медленнее рост котировок. Как только количество инвесторов, желающих продать акции, начинает превышать количество инвесторов-поку- пателей, начинается снижение цен акций. Для инвесторов, привлекавших заемные средства, возникает риск невозврата кредитов, что заставляет их продавать ранее купленные бумаги. Однако часть инвесторов верит, что снижение котировок носит временный характер, и удерживает акции и финансирует свои убытки из других источников.

3. Паника (то есть резкий обвал цен на акции) начинается, когда значительная часть инвесторов осознает, что падение котировок было не временным и начинает активно избавляться от имеющихся акций (используя терминологию Киндлебергера, можно сказать, что все инвесторы становятся инсайдерами), что ведет к ускорению падения котировок. Негативная динамика акций отпугивает потенциальных спекулянтов (то есть, в терминологии Киндлебергера, аутсайдеры уходят с рынка), что также ускоряет снижение цен на акции. На этом этапе происходит схлопывание фондового пузыря. Из-за падения акций возврат заемных средств, привлекаемых для инвестирования под залог этих акций, становится невозможным, что может стать причиной банкротства инвесторов. Если подобных случаев было много, то падение котировок на фондовом рынке может стать причиной снижения финансовой устойчивости банков и возникновения финансового кризиса.

Данная модель является одной из первых попыток объяснить динамику цены акций в период формирования фондовых пузырей. Однако модель Киндлебергера имеет ряд ключевых недостатков, которые не позволяют полноценно использовать ее для анализа фондовых пузырей на рынках развивающихся стран. В частности, в рамках жизненного цикла фондового пузыря Киндлебергера предполагается, что существует стадия между ростом (манией) и падением котировок (паника), на которой происходит замедление темпов роста цен на акции. Однако, как показывает пример китайского пузыря 2015 г. (см. рис. 1), этот период практически отсутствует. Темпы роста котировок перед началом обвала цен на акции (то есть перед началом паники на фондовом рынке) демонстрировали ускорение. При этом в последнюю неделю перед падением темпы роста несколько уменьшились по сравнению со значениями за предшествующую неделею 
(за период 01.06.2015-08.06.2015 выросли на $2,9 \%$, за период 25.05.2015-01.06.2015 рост составил $8,9 \%$ ). Однако темпы роста в 01.06.2015-08.06.2015 оставались выше средних темпов роста котировок в течение стадии мании (средний темп роста котировок за 17.11.2014 01.06.2015 составил 2,5 \%). Таким образом, стадию дистресса (во время которой должно было наблюдаться замедление темпов роста цен на акции) выделить невозможно: она либо отсутствовала, либо продолжалась менее 1 недели.

Отсутствие стадии дистресса можно объяснить более сложным, нежели в модели Киндлебергера, взаимодействием участников торгов на фондовом рынке. Нам представляется корректнее рассматривать фондовый пузырь не как результат взаимодействия инсайдеров и аутсайдеров (что лежит в основе модели Киндлебергреа), а как процесс взаимодействия рациональных и иррациональных инвесторов. Как показано в работах [2; 4-6; $15 ; 16$; и др.], фондовые пузыри являются результатом активности иррациональных инвесторов (то есть инвесторов, не способных корректно оценить фундаментальную стоимость компаний в результате влияния психологических факторов (biases)). Иррациональные инвесторы ошибаются при анализе фундаментальной стоимости акций и считают, что торгуемые компании недооценены рынком. В результате они начинают активно приобретать акции, вызывая тем самым рост котировок.

Для развивающихся стран роль иррациональных инвесторов особенно велика. Из-за относительно короткого периода существования фондовых рынков в развивающихся странах у значительной доли инвесторов может не хватать опыта и знаний. Как было показано в работе Гринвуда и Нейджела, неопытные инвесторы оказываются неспособными идентифицировать фондовый пузырь, активно приобретая переоцененные акции [10].

Действия иррациональных инвесторов оказывают влияние и на стратегии рациональных инвесторов (то есть инвесторов, ориентированных на фундаментальную стоимость и способных правильно идентифицировать фондовый пузырь): последним становится более выгодно удерживать переоцененные акции для получения спекулятивного дохода, чем играть против рынка.

Более подробный анализ роли каждой группы инвесторов в формировании фондового пузыря приведен далее.

\section{Роль иррациональных инвесторов в возникновении фондового пузыря}

Как было указано выше, значительное количество исследователей утверждают, что возникновение фондовых пузырей обусловлено действиями иррациональных инвесторов, то есть инвесторов, которые принимают решение не только на основе анализа фундаментальной стоимости, но и под влиянием своих психологических предпочтений, заставляющих отклоняться от рационального поведения (то есть инвестирование, ориентированное на

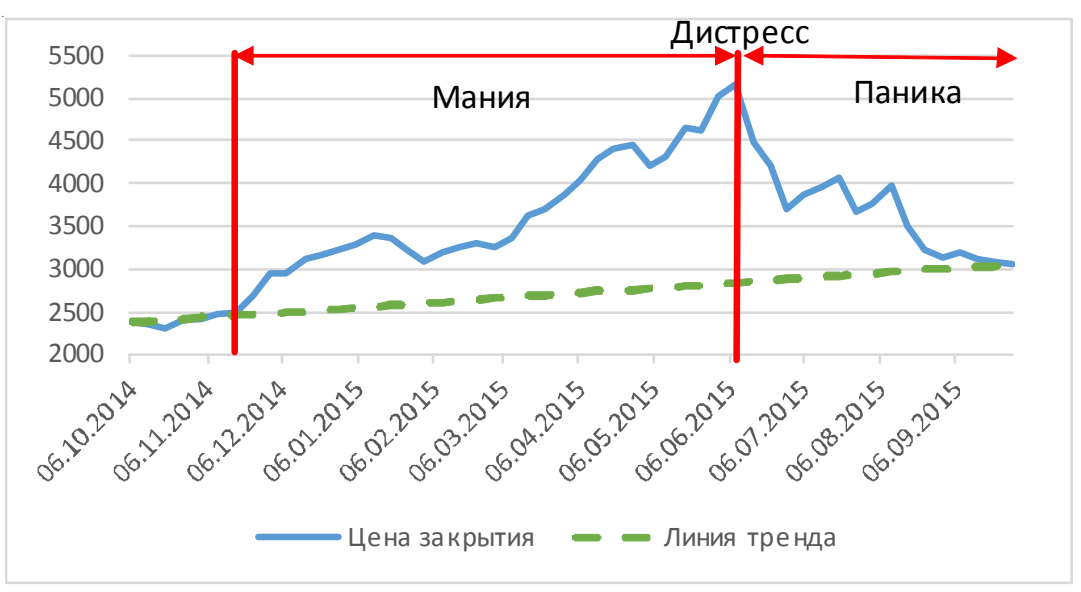

Рис. 1. Динамика Шанхайского индекса в 2014-2015 гг., юаней ${ }^{1}$

Примечание. Построено автором по данным finam.ru (URL: https://www.finam.ru (дата обращения: 01.05.2018)). 
фундаментальную стоимость). Поведенческие отклонения (biases) провоцируют ошибки иррациональных инвесторов, создавая отклонение цены от фундаментальной стоимости. Для целей анализа причин возникновения фондовых пузырей, как нам представляется, важнее всего выделить следующие поведенческие отклонения:

•Избыточный оптимизм, под влиянием которого иррациональные участники торгов прогнозируют нереалистично высокие доходы от покупки акций. Данная поведенческая особенность, по мнению Ксионга, Коха и ряда других исследователей [3; 14; 16], является одной из ключевых причин формирования фондовых пузырей, потому что именно под влиянием избыточного оптимизма иррациональные инвесторы начинают приобретать переоцененные акции.

- Эффект толпы, в рамках которого предполагается, что иррациональные инвесторы начинают следовать за большинством. В нормальных условиях ${ }^{2}$ подобное поведение не вызывает формирование фондового пузыря. Однако если большая часть иррациональных инвесторов подвержены влиянию избыточного оптимизма, то эффект толпы заставит оставшихся иррациональных инвесторов (чьи ожидания могут соответствовать действительности) приобретать переоцененные акции. В результате растет количество иррациональных инвесторов, принимающих участие в надувании пузыря ${ }^{3}$. Как отмечается в работах Люкса [12], Паттерсона и Сингха [13] и Циприани [7], эффект толпы является важной причиной появления фондовых пузырей.

Возникновение фондовых пузырей происходит, когда на рынке начинают преобладать иррациональные инвесторы, действующие одинаково. В нормальных условиях (то есть когда фондового пузыря нет) иррациональные инвесторы делают разнонаправленные ошибки, тем самым нивелируя влияние друг друга. Однако если большая часть иррациональных инвесторов становятся избыточно оптимистичными (иными словами, когда ошибки иррациональных инвесторов становятся систематическими), то тогда возможно зарождение фондового пузыря.

Ситуация, когда иррациональные инвесторы начинают систематически ошибаться, возможна в результате некоторого внешнего положительного импульса, в роли которого может выступать как единичное событие (открытие новых рынков, появление новых технологий, институциональные изменения и т. п.), так и преобладание позитивных тенденций фундаментальных факторов в течение продолжительного времени (например, сохранение высоких темпов роста экономики (что можно назвать одной из причин появления фондового пузыря в Китае в 2015 г.) или, для стран - экспортеров нефти, сохранение высоких цен на нефть). Под влиянием положительного импульса иррациональные инвесторы закладывают избыточно оптимистичные ожидания относительно перспектив роста публичных компаний, начиная массово покупать акции.

Рост котировок в результате активности иррациональных инвесторов будет восприниматься самими иррациональными инвесторами как подтверждение их ожиданий относительно перспектив развития публичных компаний. В результате увеличение цен акций будет привлекать новых иррациональных инвесторов, что, в свою очередь, станет причиной ускорения роста котировок акций.

Схлопывание пузыря, то есть обвальное падение котировок, начинается, когда иррациональные инвесторы получают информацию, очевидно показывающую ошибочность их ожиданий (внешний негативный импульс). Примером такой информации могут служить публикация финансовой отчетности торгуемых компаний (демонстрирующая худшие результаты, нежели ожидалось), публикация уточненных прогнозов роста экономики или отрасли и т. п. В результате иррациональные инвесторы начинают массово избавляться от акций, что провоцирует обвал котировок.

Однако, кроме иррациональных инвесторов, на фондовом рынке присутствуют рациональные игроки, способные распознать отклонение фактической рыночной цены от фундаментальной стоимости. Их вклад в надувание фондового пузыря мы рассмотрим далее.

\section{Роль рациональных инвесторов}

\section{в возникновении фондового пузыря}

Рост котировок, вызванный действиями иррациональных инвесторов, вызывает изме- 
нения в поведении рациональных инвесторов, в том числе институциональных. Отметим, что институциональные инвесторы (особенно хедж-фонды) часто ассоциируются с рациональными инвесторами (например, в работе [6]), поскольку они обладают штатом квалифицированных аналитиков и трейдеров и, как следствие, могут более точно оценить фундаментальную стоимость. Институциональные инвесторы могут корректно идентифицировать фондовый пузырь, что вынуждает их выбирать между двумя стратегиями: продать переоцененные акции или удерживать акции до схлопывания фондового пузыря, получая спекулятивный доход.

Первая стратегия (продажа акций) может включать в себя короткие продажи и иные способы получения доходов от снижения котировок в условиях схлопывания фондового пузыря (например, с помощью фьючерсов и иных производных ценных бумаг). Данная стратегия вытекает из политики рациональных инвесторов ориентироваться на фундаментальную стоимость: если рыночные котировки превышают фундаментальную стоимость, то в будущем будет коррекция цен, что позволит получить рациональному инвестору прибыль. Однако такая стратегия имеет ряд недостатков:

1. Фондовый пузырь может сохраняться достаточно долго, так что рациональные инвесторы, играющие против пузыря, получат убытки и будут вынуждены закрыть свои позиции и покинуть рынок.

2. Деятельность инвестиционных фондов зависит от их привлекательности для инвесторов. Если фонды правильно идентифицировали фондовый пузырь, а их иррациональные клиенты пузыря не заметили, то фонды вынуждены будут покупать переоцененные акции, чтобы не потерять клиентов.

Таким образом, если инвестиционный фонд откажется от участия в надувании пузыря, для него существует вероятность потери клиентов и закрытия. Для иллюстрации можно привести опыт Джулиана Робертса (Julian Roberts) - менеджера инвестиционного фонда Tiger Hedge Fund. В 1999 г. он отказался инвестировать в акции высокотехнологичных компаний, утверждая, что их стоимость на тот момент была крайне завышена. Его позиция подтвердилась в 2000 г., когда лопнул пузырь дот-комов. Однако к тому времени Tiger Hedge Fund уже был закрыт, поскольку его доходность в 1999-2000 гг. была существенно ниже доходности других фондов, которые инвестировали в акции высокотехнологичных компаний.

Вторая стратегия (удержание переоцененных акций для получения спекулятивного дохода) лишена недостатков первой и позволяет фондам сохранять своих клиентов. Кроме того, как показывают исследования, данная стратегия является наиболее выигрышной в условиях надувания фондового пузыря. Например, как следует из работы Брюннэрмейера и Нейджела [6], во время пузыря доткомов на американском фондовом рынке хедж-фонды активно приобретали переоцененные акции. И для них покупка переоцененных акций оказалась прибыльной: совокупные прибыли таких фондов от роста котировок акций оказались выше потерь, возникших при резком падении цен на акции в результате схлопывания пузыря: фонды успели продать акции по ценам выше цены покупки (при этом многие фонды могли продать акции во время сдутия пузыря, однако успели сохранить свою спекулятивную прибыль).

Эффективность второй стратегии будет зависеть от способности рационального инвестора правильно найти время покупки и продажи акций. Если рациональные инвесторы ожидают, что рост котировок будет какое-то время сохраняться, то им выгоднее приобретать переоцененные акции. Спрос со стороны инвестиционных фондов (обладающих более обширными ресурсами по сравнению с иррациональными индивидуальными инвесторами) будет способствовать росту котировок акций. Как указывалось выше, рост котировок привлекает новых иррациональных инвесторов, что позволяет рациональным инвесторам получить спекулятивный доход. Для реализации спекулятивного дохода рациональным инвесторам необходимо правильно определить время продажи акций. Если опоздать с продажей, то спекулятивные сделки принесут убыток. Напротив, слишком ранняя продажа позволит зафиксировать прибыль, однако приведет к потере потенциального спекулятивного дохода, который рациональный инвестор мог бы получить, если бы удерживал акции чуть дольше. 
Как было показано в работах [6; 10], рациональные инвесторы будут ждать внешнего негативного импульса, который станет причиной изменения поведения иррациональных инвесторов. Как только произойдет негативный импульс (в роли которого, как указывалось выше, могут выступать ужесточение регулирования, корректировка прогнозов и т. п.), рациональные инвесторы начнут быстро избавляться от акций, пока иррациональные инвесторы не успели изменить свои стратегии и спровоцировать обвал котировок. Схематично взаимодействие между рациональными и иррациональными инвесторами, которое ведет к надуванию фондового пузыря, изображено на рисунке 2 .

Обобщая взаимодействие рациональных и иррациональных инвесторов, необходимо отметить, что в процессе надувания фондового пузыря ключевую роль играют иррациональные инвесторы. Фондовый пузырь возни- кает и надувается, пока на рынке преобладают иррациональные инвесторы с избыточно оптимистичными ожиданиями. Схлопывание фондового пузыря происходит, когда поступает информация, вынуждающая иррациональных инвесторов пересмотреть свои ожидания и начать продавать имеющиеся акции.

Стратегия рациональных инвесторов представляет собой реакцию на действия иррациональных инвесторов. Основная задача рациональных инвесторов - правильно определить время схлопывания фондового пузыря и успеть продать акции, получив максимальный спекулятивный доход.

Построенная нами схема взаимодействия рациональных и иррациональных инвесторов (приведенная на рисунке 2) принципиально отличается от схемы, описанной Киндлебергером, тем, что наши рассуждения допускают дальнейшее присутствие рациональных инвесторов на рынке и после того момен-
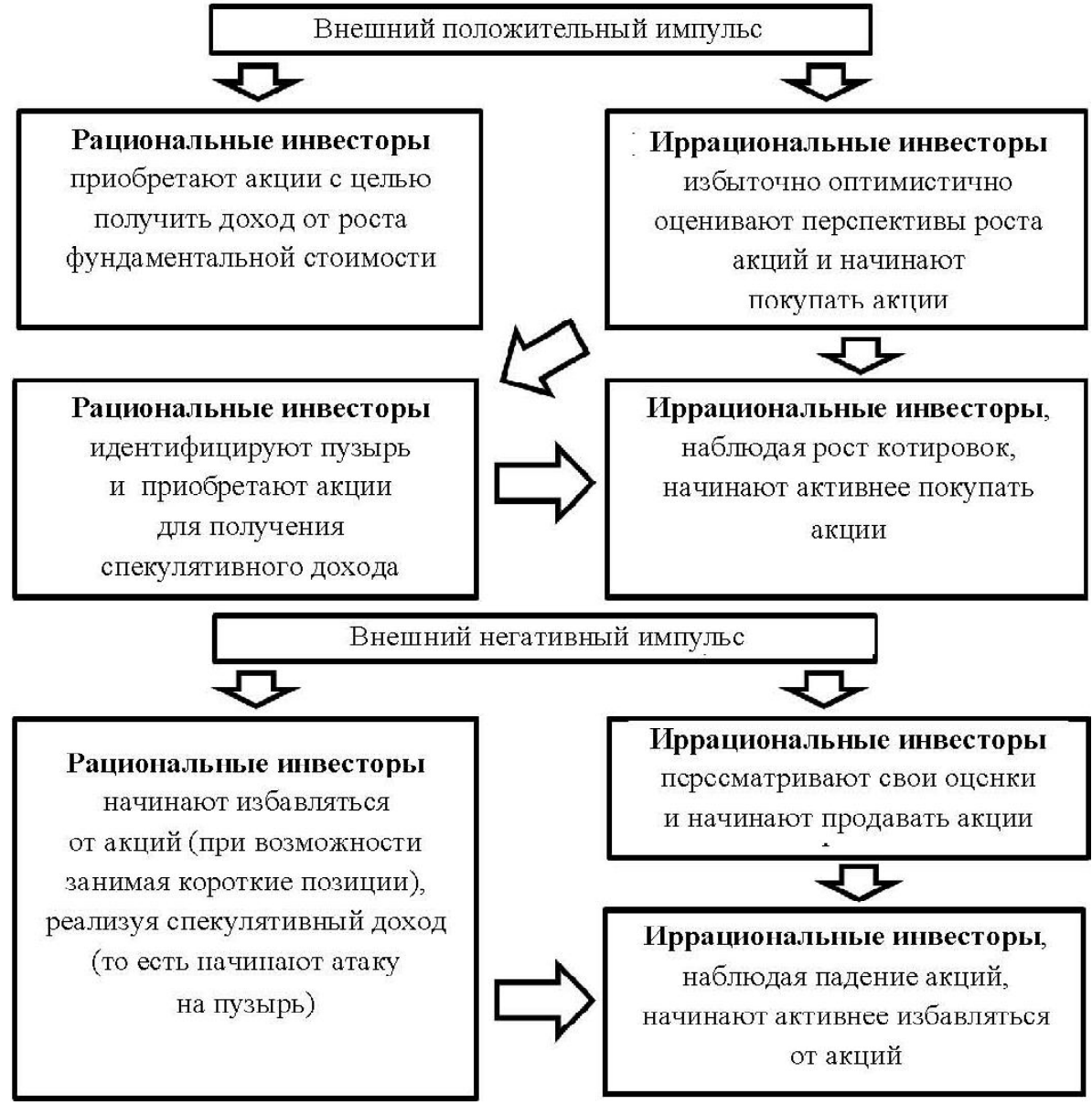

Рис. 2. Роль рациональных и иррациональных инвесторов в надувании фондового пузыря Примечание. Составлено автором. 
та, как они обнаружат появление пузыря, в то время как модель Киндлебергера постулирует, что рациональные инвесторы покинут рынок в момент выявления ими пузыря. Соответственно, наш подход требует модификации профиля жизненного цикла фондового пузыря в соответствии со значимыми особенностями поведения инвесторов на развивающихся фондовых рынках.

\section{Модифицированная модель жизненного цикла фондового пузыря на развивающихся рынках}

На основе сформированной выше схемы взаимодействия рациональных и иррациональных инвесторов нами были выделены пять стадий жизненного цикла фондового пузыря. Поскольку в отличие от схемы Киндлебергеpa, наша модель отталкивается от взаимодействия рациональных и иррациональных инвесторов, она позволяет объяснить отсутствие стадии дистресса, а также определить, какие меры может предпринять регулятор для предотвращения или схлопывания фондового пузыря, и как эти меры будут оказывать влияние на котировки. На основе нашей авторской модели можно выделить несколько этапов жизненного цикла фондового пузыря:

1. Первичный импульс. Начинается устойчивый рост котировок акций за счет фундаментальных факторов. Как мы описывали выше, это может быть как единоразовое событие, так и длительное сохранение благоприятных условий (на рисунке 2 это представлено как положительный внешний импульс). На данном этапе динамика котировок акций на вторичном рынке отражает изменение фундаментальной стоимости компаний. Фондового пузыря еще нет, однако образовались предпосылки для его зарождения, поскольку положительная динамика фундаментальной стоимости начинает привлекать избыточно оптимистичных иррациональных инвесторов.

2. Иррациональный рост котировок. Растущие котировки привлекают новых иррациональных инвесторов. Массовая покупка иррациональными инвесторами акций начинает провоцировать рост цен на акции. Поскольку среди инвесторов все большую долю занимают иррациональные, котировки компаний начинают превышать их фундаментальную стоимость. Рациональные инвесторы, видя образование фондового пузыря и усиливающееся влияние иррациональных инвесторов, вынуждены отходить от стратегии, ориентированной на фундаментальную стоимость, в пользу спекулятивных покупок. Именно на этом этапе происходит фактическое возникновение фондового пузыря.

3. Спекулятивный взрыв. Большинство рациональных инвесторов стали использовать спекулятивные стратегии на рынке. Иррациональные инвесторы, наблюдая рост котировок, также начинают активнее покупать акции, думая, что происходит рост фундаментальной стоимости. Темп роста котировок акций ускоряется, а фондовый пузырь достигает своих максимальных размеров.

4. Схлопывание пузыря. Поступает негативная информация (на рисунке 2 это соответствует негативному внешнему импульсу). Данная информация выступает в роли сигнала рациональным инвесторам для начала атаки на рынок - агрессивных продаж (включая короткие продажи), что провоцирует снижение цен на акции. Иррациональные инвесторы, получив негативную информацию и наблюдая падение котировок, осознают ошибочность своих избыточно оптимистичных ожиданий и также начинают продавать акции. В результате падение котировок ускоряется и возникает паника на рынке. Фондовый пузырь сдувается до полного исчезновения.

5. Стабилизация. Схлопывание фондового пузыря завершается после падения рыночных цен до уровня фундаментальной стоимости (или ниже). После этого использование спекулятивных стратегий рациональными инвесторами становится неэффективным, и они возвращаются к стратегиям, основанным на анализе фундаментальных ценообразующих показателей. На этой стадии ошибки иррациональных инвесторов вновь перестают быть односторонними и систематическими, и устойчивые отклонения рыночных цен акций от их фундаментальной стоимости перестают иметь место.

В авторской модели жизненного цикла фондового пузыря процесс надувания и сдутия пузыря определяется характером взаимодействия между рациональными и иррациональными инвесторами. Действия иррациональных 
инвесторов, как мы указывали выше, становятся причиной возникновения пузыря, в то время как рациональные инвесторы корректируют свои действия в ответ на изменившуюся ситуацию на фондовом рынке. Однако на 4-й стадии рациональные инвесторы перехватывают инициативу, провоцируя спад котировок и панику среди иррациональных инвесторов.

В рамках описанной нами модели предполагается, что развитие фондового пузыря происходит естественным путем. Однако можно ожидать, что регулятор будет предпринимать меры по уничтожению фондового пузыря, являющегося одним из проявлений финансовой нестабильности и способного нанести вред финансовой системе и экономике страны в целом. Меры регулятора могут остановить развитие фондового пузыря на ранних стадиях жизненного цикла или спровоцировать более быстрое наступление 4-й стадии, обеспечив схлопывание фондового пузыря без значительного ущерба для финансовой системы.

Необходимо учитывать, что разные меры по-разному воздействуют на рациональных и иррациональных инвесторов. Даже в развитых странах, где у участников торгов на фондовом рынке больше опыта, иррациональные инвесторы могут проигнорировать меры регулятора по схлопыванию фондового пузыря (наиболее яркий пример - увеличение учетной ставки в США в период пузыря дот-комов, которое не привело к схлопыванию пузыря [1, с. 27]). На наш взгляд, для развивающихся стран данное утверждение также верно.

Поэтому меры противодействия фондовым пузырям должны дифференцироваться в зависимости от стадии, на которой пузырь был обнаружен. Выбор мер должен определяться в зависимости от того, какая группа инвесторов определяет динамику котировок.

В следующем подразделе мы приводим соотношение стадий жизненного цикла фондового пузыря и мер по сближению рыночных цен и фундаментальной стоимости акций.

\section{Регулятивные меры противодействия фондовым пузырям на развивающихся рынках}

Противодействие фондовым пузырям является одним из важных элементов поли- тики регулятора по обеспечению финансовой стабильности. Меры по противодействию фондовым пузырям, предпринимаемые регулятором, целесообразно дифференцировать в зависимости от стадии, на которой регулятором был обнаружен пузырь. С целью отбора наиболее эффективных мер для каждой стадии мы проанализировали через призму нашей модели жизненного цикла пузыря те инструменты, которые доступны регулятору.

Укрупненно все инструменты, направленные на противодействие фондовым пузырям, можно разделить на две большие группы:

1. Профилактические меры, действующие постоянно (независимо от наличия на фондовом рынке пузыря). Цель данных мер создать такие условия, чтобы фондовый пузырь не мог возникнуть. К данной группе можно отнести институциональные преобразования. Например, ввод требований к квалификации управляющих инвестиционными фондами (которых можно рассматривать в качестве рациональных инвесторов). Также возможно ужесточение требований к качеству информации, предоставляемой эмитентами. Такими способами можно снизить вероятность возникновения избыточного оптимизма у иррациональных инвесторов и тем самым не допустить формирования критической массы таких инвесторов, достаточной для надувания фондового пузыря.

Также к профилактическим мерам институционального характера можно отнести снижение регулятором ограничений на совершение коротких продаж: это увеличит возможности рациональных инвесторов на 1-й стадии элиминировать действия иррациональных инвесторов. Реализовать данную меру можно как за счет расширения перечня компаний, по которым возможны короткие продажи (например, в России данный перечень ограничен закрытым списком наиболее ликвидных ценных бумаг), так и давая возможность крупным институциональным инвесторам формировать производные ценные бумаги, позволяющие играть на понижение.

Общая цель вышеуказанных мер - остановить развитие потенциального фондового пузыря на первой же стадии (то есть предотвратить его возникновение). Однако если фондовый пузырь перешел на более поздние ста- 
дии, то данные меры не смогут оказывать существенного влияния.

2. Активные меры, используемые, когда фондовый пузырь все же возник и необходимо предпринять меры для его схлопывания. Такие меры следует предпринимать на 2-й или 3-й стадиях, чтобы спровоцировать переход к 4-й стадии, пока фондовый пузырь не достиг значительных размеров, тем самым уменьшив вред от него. Эти меры должны привести к снижению котировок переоцененных акций за счет влияния на их фундаментальную стоимость. Применение активных мер необходимо, если пассивные меры не были предприняты в результате наличия лагов экономической политики. Так, регулятор мог пропустить 1-ю стадию фондового пузыря, идентифицировав его только на 2-й или 3-й (лаг обнаружения). Более того, регулятор мог идентифицировать риски зарождения фондового пузыря на 1-й стадии, но не успеть разработать и принять комплекс мер по предотвращению реализации этих рисков (лаг принятия решения). Также возможна ситуация, когда регулятор успел предпринять необходимые действия, однако они не успели оказать необходимого эффекта (лаг воздействия), в результате чего пузырь достиг 2-й стадии.

Эффективность активных мер также может быть снижена в результате лагов экономической политики, однако для них характерен меньший лаг воздействия, поскольку данные меры оказывают прямое влияние на цены, в отличие от пассивных мер. В качестве инструментов активных мер можно выделить:

- Ужесточение ДКП (в том числе за счет увеличения учетной ставки), которая позволит схлопнуть фондовый пузырь за счет нескольких каналов. Во-первых, увеличение учетной ставки негативно влияет на фундаментальную стоимость, поскольку снижает приведенную стоимость будущих денежных потоков. Во-вторых, рост ставок ведет к росту стоимости обслуживания долга для компаний, делая их менее рентабельными, снижая привлекательность для всех групп инвесторов. В-третьих, увеличение ставок может коснуться непосредственно инвесторов, привлекающих заемные средства для покупки акций: в этом случае им придется уменьшить объем покупок. В то же время данные меры могут быть более эффективными на 3-й стадии, когда рациональные инвесторы ждут возможности для активных продаж. На 2-й стадии рост ставки вызовет лишь краткосрочное снижение, после которого положительный тренд восстановится (что можно было наблюдать в США во время пузыря дот-комов [1, с. 27]). Подобная неэффективность ДКП на 2-й стадии обусловлена тем, что рациональных инвесторов, занявших спекулятивные позиции, может быть недостаточно для схлопывания пузыря, а иррациональные инвесторы могут не оценить эффект от повышения ставки на фундаментальную стоимость. В то же время на 3-й стадии все рациональные инвесторы заняли спекулятивные позиции и ожидают возможности для начала продаж акций. Снижение котировок в результате реализации данной возможности, спровоцированной ростом учетной ставки совместно с негативными новостями (к которым относится повышение учетной ставки), вынудит иррациональных инвесторов продавать свои акции, что и вызовет переход на 4-ю стадию жизненного цикла фондового пузыря.

- Вербальные интервенции, с помощью которых можно информировать иррациональных инвесторов, что их оценки избыточно оптимистичны, что может снизить их активность и послужить сигналом для активных продаж рациональными инвесторами. Однако применение таких мер требует высокого влияния позиции регулятора на поведение инвесторов, что достигнуто не во всех развивающихся странах.

- Введение запрета на маржинальную торговлю ${ }^{4}$, что сделает менее выгодными спекулятивные сделки рациональных инвесторов, а также ограничит ресурсы иррациональных инвесторов для подпитки пузыря. Введение данного запрета вызовет продажи акций, поскольку инвесторы, которые совершали маржинальные сделки, будут вынуждены их закрывать для выполнения требований регулятора. Данная мера, в частности, стала одной из причин схлопывания упомянутого ранее китайского фондового пузыря 2015 года 5 .

Активная распродажа акций приведет к снижению котировок, что может послужить причиной схлопывания пузыря. Но даже если схлопывания не произойдет, а снижение цен 
на акции будет носить временный характер, потери инвесторов при будущем схлопывании окажутся меньше, так как инвесторам не придется закрывать взятые на себя долговые обязательства. Как указывалось выше, данная мера может рассматриваться как причина схлопывания китайского фондового пузыря в 2015 году.

Таким образом, профилактические меры могут применяться только на 1-й стадии, когда фондового пузыря еще нет, а иррациональные инвесторы не оказывают существенного влияния на котировки. Активные меры необходимо принимать на 2-й, или, в крайнем случае, на 3-й стадии, чтобы уменьшить оптимизм иррациональных инвесторов и спровоцировать рациональных инвесторов продавать акции.

\section{Выводы}

Фондовые пузыри являются сложным финансовым феноменом, возникающим в результате активности иррациональных инвесторов, то есть инвесторов, не способных корректно определить фундаментальную стоимость компаний и исходящих из избыточно оптимистичных ожиданий. Поскольку для развивающихся рынков характерно преобладание иррациональных инвесторов, модели, разработанные на основе анализа развитых рынков (в том числе модель Киндлебергера), не могут быть применены для развивающихся стран.

Нами была построена схема взаимодействия рациональных и иррациональных инвесторов, в ходе которого происходит надувание фондового пузыря. По нашему мнению, ключевую роль играют иррациональные инвесторы: их избыточный оптимизм провоцирует рост котировок выше фундаментальной стоимости. Рациональные инвесторы в ответ на формирование фондового пузыря начинают использовать спекулятивные стратегии, стараясь получить максимальный доход от роста котировок. При этом, как только рост завершается, рациональные инвесторы стараются избавиться от переоцененных акций, способствуя панике среди иррациональных инвесторов и обвалу котировок.

На основе данной схемы взаимодействия мы выделили 5 стадий жизненного цикла фондового пузыря, в зависимости от соот- ношения действий рациональных и иррациональных инвесторов и их стратегий. В зависимости от стадии будет различаться набор мер по противодействию фондовым пузырям. Так, на 1-й стадии (когда возникают предпосылки зарождения пузыря) необходимо использовать пассивные меры, чтобы ограничить долю иррациональных инвесторов. На 2-й и 3-й стадиях (когда происходит надувание пузыря и достижение ценовых максимумов) требуется предпринимать активные меры для ускоренного схлопывания пузыря в результате давления на иррациональных инвесторов и создания условий распродажи для рациональных инвесторов.

\section{ПРИМЕЧАНИЯ}

1 Фондовый пузырь идентифицировался как отклонение фактической цены от долгосрочного тренда, рассчитанного на основе линейной экстраполяции цен.

2 Данный термин описывает ситуацию, когда рыночные цены в целом соответствуют фундаментально обоснованному уровню, а иррациональные инвесторы не совершают систематических односторонних ошибок, то есть некоторые из них занижают стоимость акций, а некоторые - завышают, и в результате их ошибки элиминируют свое влияние, не давая ценам акций отклониться от фундаментального уровня.

${ }^{3}$ Иррациональных инвесторов в этом случае можно разделить на 2 группы: оптимистов и имитаторов. Таким образом, в условиях формирования фондового пузыря инвесторы-оптимисты будут покупать переоцененные акции, потому что ошибаются в своих оценках, а инвесторы-имитаторы начнут повторять действия инвесторов-оптимистов.

${ }^{4}$ Маржинальная торговля - покупка акций с использованием заемных средств.

5 Подробнее об этом см.: https:// www.theguardian.com/world/2015/jan/19/chinamarket-margin-trading-ban-shanghai-index.

\section{СПИСОК ЛИТЕРАТУРЫ}

1. Чиркова, Е. В. За и против регулирования финансовых пузырей монетарными методами / Е. В. Чиркова // Корпоративные финансы. - 2011. № 2 (18). - C. 24-32.

2. Allen, F. Churning bubbles / F. Allen, G. Gorton // The Review of Economic Studies. - 1993. Vol. 60, № 4. - P. 813-836. 
3. Bank lending and real estate in Asia: Market optimism and asset bubbles / W. T. H. Koh [et al.] // Journal of Asian Economics. - 2005. - Vol. 15, № 6. P. 1103-1118.

4. Blanchard, O. J. Bubbles, rational expectations and financial markets / O. J. Blanchard, M. W. Watson. - Electronic text data. - NBER Working Paper No. 945 (Also Reprint No. r0374). Cambridge, issued in July 1982. - 30 p. - Mode of access: http://www.nber.org/papers/w0945.pdf. Title from screen.

5. Bris, A. Efficiency and the bear: Short sales and markets around the world / A. Bris, W. N. Goetzmann, N. Zhu // The Journal of Finance. - 2007. - Vol. 62, № 3. - P. 1029-1079.

6. Brunnermeier, M. K. Hedge funds and the technology bubble / M. K. Brunnermeier, S. Nagel // The Journal of Finance. - 2004. - Vol. 59, № 5. P. 2013-2040.

7. Cipriani, M. Herd behavior and contagion in financial markets / M. Cipriani, A. Guarino // The BE Journal of Theoretical Economics. - 2008. - Vol. 8, № 1 . - P. 1-54.

8. Duffie, D. Securities lending, shorting, and pricing / D. Duffie, N. Garleanu, L. H. Pedersen // Journal of Financial Economics. - 2002. - Vol. 66, № 2. - P. 307-339.

9. Friedman, M. The lag in effect of monetary policy/ M. Friedman // Journal of Political Economy. 1961. - Vol. 69, № 5. - P. 447-466.

10. Greenwood, R. Inexperienced investors and bubbles / R. Greenwood, S. Nagel // Journal of Financial Economics. - 2009. - Vol. 93, № 2. P. 239-258.

11. Hong, H. Security analysts' career concerns and herding of earnings forecasts / H. Hong, J. D. Kubik, A. Solomon // The Rand journal of economics. - 2000.P. 121-144.

12. Lux, T. Herd behaviour, bubbles and crashes / T. Lux // The economic journal. - 1995. P. 881-896.

13. Patterson, D. M. Herding During the Stock Market Bubble: An Intraday Analysis / D. M. Patterson, V. Singh // SSRN. - Electronic data. - May 2015. Mode of access: https://papers.ssrn.com/sol3/ papers.cfm?abstract_id $=2603399$. - Title from screen.

14. Scheinkman, J. Heterogeneous beliefs, speculation and trading in financial markets / J. Scheinkman, W. Xiong // Paris-Princeton Lectures on Mathematical Finance 2003. - Springer Berlin Heidelberg, 2004. - P. 217-250.

15. Shiller, R. J. Irrational exuberance/ R. J. Shiller.Princeton UP, 2000. - 392 p.

16. Xiong, W. Bubbles, crises, and heterogeneous beliefs / W. Xiong. - NBER Working Paper No. w18905. - Cambridge, march 2013. - 52 p.

\section{REFERENCES}

1. Chirkova E.V. Za i protiv regulirovaniya finansovykh puzyrey monetarnymi metodami [Pros and Cons of Financial Bubbles Regulation by Monetary Methods]. Journal of Corporate Finance Research, 2011, no. 2 (18), pp. 24-32.

2. Allen F., Gorton G. Churning bubbles. The Review of Economic Studies, 1993, vol. 60, no. 4, pp. 813-836.

3. Koh W.T.H., et al. Bank lending and real estate in Asia: Market optimism and asset bubbles. Journal of Asian Economics, 2005, vol. 15, no. 6, pp. 1103-1118.

4. Blanchard O.J., Watson M.W. Bubbles, rational expectations and financial markets. NBER Working Paper No. 945 (Also Reprint No. r0374). Cambridge, 1982. 30 p. URL: http://www.nber.org/ papers/w0945.pdf.

5. Bris A., Goetzmann W.N., Zhu N. Efficiency and the bear: Short sales and markets around the world. The Journal of Finance, 2007, vol. 62, no. 3, pp. 1029-1079.

6. Brunnermeier M.K., Nagel S. Hedge funds and the technology bubble. The Journal of Finance, 2004, vol. 59, no. 5, pp. 2013-2040.

7. Cipriani M., Guarino A. Herd behavior and contagion in financial markets. The BE Journal of Theoretical Economics, 2008, vol. 8, no. 1, pp. 1-54.

8. Duffie D., Garleanu N., Pedersen L.H. Securities lending, shorting, and pricing. Journal of Financial Economics, 2002, vol. 66, no. 2, pp. 307-339.

9. Friedman M. The lag in effect of monetary policy. Journal of Political Economy, 1961, vol. 69, no. 5, pp. 447-466.

10. Greenwood R., Nagel S. Inexperienced investors and bubbles. Journal of Financial Economics, 2009, vol. 93, no. 2, pp. 239-258.

11. Hong H., Kubik J. D., Solomon A. Security analysts' career concerns and herding of earnings forecasts. The Rand journal of economics, 2000, pp. 121-144.

12. Lux T. Herd behaviour, bubbles and crashes. The economic journal, 1995, pp. 881-896.

13. Patterson D.M., Singh V. Herding During the Stock Market Bubble: An Intraday Analysis. SSRN, 2015. URL: https://papers.ssrn.com/sol3/ papers.cfm?abstract_id=2603399.

14. Scheinkman J., Xiong W. Heterogeneous beliefs, speculation and trading in financial markets. Paris-Princeton Lectures on Mathematical Finance 2003. Springer Berlin Heidelberg, 2004, pp. 217-250.

15. Shiller R.J. Irrational exuberance. Princeton UP, 2000. 392 p.

16. Xiong W. Bubbles, crises, and heterogeneous beliefs. NBER Working Paper No. w18905. Cambridge, 2013. $52 \mathrm{p}$. 
Е.Б. Нетунаев. Жизненный цикл фондового пузыря в развивающихся странах

\section{Information about the Author}

Evgeniy B. Netunaev, Leading Consultant of Business Valuation Department, Baker Tilly Rus Consulting JSC; Postgraduate Student, Lomonosov Moscow State University, Khoroshevskoe shosse, 32A, 123007 Moscow, Russian Federation, Netynaev.evgeny@gmail.com.

\section{Информация об авторе}

Евгений Борисович Нетунаев, ведущий консультант департамента оценки бизнеса $\mathrm{AO}$ «Бейкер Тилли Рус Консалтинг»; аспирант, Московский государственный университет им. М.В. Ломоносова, Хорошевское шоссе, 32А, 123007 г. Москва, Российская Федерация, Netynaev.evgeny@gmail.com. 